\title{
WIOSNA SZUKAŁA, PATRYCJA TOMCZAK, JUDYTA WACHOWSKA (RED.), KSIĄŻKA DLA JULIA. CORTÁZAR PO LATACH. POZNAŃ: WYDAWNICTWO NAUKOWE UAM, 2019
}

A esta hora-dijo el indio-todo se confunde y reconcilia [...].

César Aira, Ema, la cautiva

Estamos viviendo, según parece, en un ambiente intelectual en el que cada vez más fuertes se ven las tendencias a relativizar las dinámicas identitarias, a quebrar oposiciones duales y jerárquicas, incluso las más elementales y, aparentemente, obvias. Estamos reflexionando sumergido/as en un mundo donde el postantropocentrismo está cambiando la percepción de nuestro -el de los seres humanos- rol en el universo, por un lado problematizando, a medida que avanzan las investigaciones sobre la inteligencia artificial, la centralidad de la inteligencia orgánica - la de carbono- frente a la inteligencia de silicio y aún a las formas de vida basadas en azufre, premonizadas ya por las novelas de Stanisław Lem, y, por el otro, subrayando la importancia de la inteligencia y la sensibilidad animal y vegetal. Los binomios que no hace mucho eran fundamentales para pensarnos a nosotros mismos y nuestra relación con el mundo -cultura/naturaleza, progreso/retraso, centro/periferia, ciudad/campo, lo racional/lo irracional, lo humano/lo no humano, modernidad/postmodernidad, cultura alta/cultura de masas, sexo/género, varón/mujer, etc.- parecen ir diluyéndose y perdiendo su capacidad interpretativa. Julio Cortázar, como autor del ensayo titulado "Del sentimiento de no estar del todo", podría, entonces, verse como patrón de esta, como la llamó Zygmunt Bauman, (post)modernidad líquida (Liquid Modernity, 2000), dentro de la cual, además, gracias a la globalización y la intensificación de los contactos interculturales, van confrontándose -y no necesariamente reconciliándose, como reza el epígrafe de César Aira citado arriba- perspectivas muy heterogénicas.

Lo/as autore/as de Książka dla Julia. Cortázar po latach, libro colectivo coordinado por Wiosna Szukała, Patrycja Tomczak y Judyta Wachowska, parecen adoptar la postura cortazariana -que consistiría en diluir fronteras, en ,saltar entre”, como los conejos de la Carta a una señorita en París - en el sentido de que, a la hora de comentar la obra del maestro, se mueven con soltura entre campos muy diferentes, borrando las líneas que separan lo íntimo de lo académico, lo personal de lo institucional, lo literario de lo político, lo polaco de lo argentino, lo original de lo traducido, lo propio de lo otro o, last but not least, la literatura de otras artes. El resultado, es un tomo muy polifacético, lo que, sin duda, le gustaría a Cortázar 
quien, según subraya su traductora-leyenda, Zofia Chądzyńska, en el texto conmemorativo ${ }^{1}$ que abre el libro, él mismo "fue el rey de las facetas" (p. 16 traducción propia). El texto de Chądzyńska, que murió en 2003, habiendo traducido casi toda la obra del Gran Cronopio que, por lo visto, se mostraba cariñosamene (o no) sospechoso de sus traducciones tan exitosas, porque "no se sabe qué es lo que escribes allí, che" (p. 16)- es un testimonio sumamente conmovedor por parecer excepcionalmente sincero. Lo vemos, sobre todo, en los fragmentos que describen los intentos, nunca fáciles, de entenderse mutuamente, por cierto más como dos seres humanos que un escritor y su traductora (p. 18) o, todavía con más fuerza, los choques ideológicos e interculturales entre ambos -como cuando Cortázar, fervoroso izquierdista latinoamericano, no entiende el rechazo que provoca la realidad comunista en Polonia (pp. 18-19).

Y si hablamos de choques entre diferentes perspectivas, uno de los ejes temáticos principales del tomo, visible ya en el título, es la cuestión temporal, o sea, el contraste -en diversos ámbitos- entre los tiempos del boom y la actualidad, así como la pregunta implícita: ¿qué queda de Cortázar, "pasado el tiempo"? En este sentido, Marta Jordan, otra de lo/as traductore/as del autor de Rayuela, en su texto igualmente personal que el de Chądzyńska, y dividido significativamente en tres partes tituladas: "Ayer", "Hoy" y "Mañana", parece llena de esperanza: por una parte, recordando la Polonia gris de los años 70 describe a Cortázar como a una suerte de salvador que "nos regalaba la llave de un jardín maravilloso" (p. 32), y por otra, buscando huellas cortazarianas en la literatura polaca contemporánea entre otros, en la prosa del Premio Nobel reciente, Olga Tokarczuk-sugiere que la obra del Gran Cronopio esconde todavía, para todos nosotros, muchas sorpresas. Un poco menos optimista resulta ser el texto de Mario Muñoz titulado melancólicamente "Cuando creíamos que el mundo les peretenecía a los cronopios". Muñoz, que se concentra más en lo político que en lo literario, se presenta como la voz de toda una generación que en los años 50 y 60 lo descubrió a Cortázar como a un profeta de la revolución, del hombre nuevo, de "un nuevo Renacimiento" (p. 51), y que, desilusionada después de los proyectos revolucionarios, lo mira al autor de Libro de Manuel como a un escritor de otra época -más bella, sin duda, pero ya muy lejana.

El ensayo de Muñoz, que cierra el primer apartado del libro, titulado "Recuerdos", es una buena introducción a lo que sigue en el segundo, dedicado precisamente al tema de los vínculos entre la literatura cortazariana y la revolución. Las autoras de esta parte del tomo estudian el compromiso y el legado político de la obra de Cortázar desde tres perspectivas diferentes: Iwona Krupecka, partiendo de "la sensible cuestión" (p. 61) del comunismo, socialismo y marxismo, inscritos en muchos de sus textos, busca sus filiciones filosóficas en el pensamiento de la Escuela de Frankfurt (el gato Adorno pulula incluso por las tapas del libro); Judyta Wachowska, volviendo a Libro de Manuel, o sea, uno de sus libros más politizados, reflexiona sobre su lugar dentro de la tradición revolucionaria latinoamericana; y Agnieszka Kaczmarek, desde un punto de vista más antropológico -sobre su relación con los movimientos contestatorios de los años 60 y con los actuales. Krupecka insiste en la visión de la literatura cortazariana como una suerte de teoría crítica, cuyo compromiso se manifestaría más en la forma asistémica de Libro de Manuel que en sus contenidos explicítamente políticos,

\footnotetext{
${ }^{1}$ Publicado originalmente en Literatura na Świecie [Literatura en el Mundo], 1985: 2, un año después de la muerte de Cortázar.
} 
y cuyo objetivo sería, como quería Juan Carlos Curutchet (Julio Cortázar o la crítica de la razón pragmática, 1972), la lucha contra la pragmatización y la instrumentalización de la razón humana, con tal de defender la subjetividad individual en las sociedades modernas. Wachowska formula una pregunta muy interesante que admite muchas respuestas incluso contradictorias: ¿qué pensaría Manuel -que ahora tiene más de cuanrenta años y sus propias convicciones políticas, a lo mejor devora los libros de Bolaño, es eco-activista y feminista, o al contrario- a la hora de leer hoy en día el libro que le fue dedicado? Kaczmarek, por su parte, introduce una división -según parece, bastante pesimista- entre los hipsterscronopios, que en las décadas anteriores contestaban la realidad, y los hipsters-famas actuales, que anidan comódamente dentro de ella.

Estas reflexiones, que, por otra parte, casi siempre parten de uno u otro fragmento de Cortázar, en los dos últimos apartados del tomo ceden el lugar al análisis detallado de varios cuentos. Agnieszka Doda-Wyszyńska, recurriendo a la teoría del kitch de Hermann Broch y al pensamiento de Jaques Rancière, construye a base de "Continuidad de los parques" una teoría de lectura. Wiosna Szukała, tomando como punto de partida las numerosas teorías de lo fantástico en Cortázar, propone una nueva lectura del cuento titulado "Después del almuerzo", basada en la división entre paidia i ludus -dos aspectos del concepto de juego- introducida por Roger Caillois, mientras que Barbara Stawicka-Pirecka añade una variación casi poética sobre los motivos del cuento "La noche boca arriba" y Arkadiusz Żychliński, en el último texto del tercer apartado del tomo, desarrolla una interpretación sumamente ingeniosa de "La noche de Mantequilla", volviendo, no sin cierta malicia, al concepto de literatura comprometida.

En el cuarto apartado los análisis continúan, con la diferencia de que el protagonismo es aquí otorgado a la comparatística -intercultural e interdisciplinaria. Aránzazu Calderón Puer$\mathrm{ta}^{2}$ lee el cuento "Parasol" ["Paraguas"] de la escritora polaca Natasza Goerke, situándolo en el contexto de dos cuentos de Cortázar - "Axolotl" y "Lejana"- y describiendo el proceso de acceder a "la epifanía metaliteraria" (p. 216) que experimentan los protagonistas de los textos. Wojciech Sawala, por su parte, se concentra en lo que llama "la arquitectura de la ausencia" (p. 221) en varios cuentos cortazarianos, sobre todo en "Carta a una señorita en París", "Los testigos" o "Casa tomada", comparando las maneras de presentar "el triunfo del orden impersonal [...] sobre el individuo" (p. 240) en ellos y en la obra de Bruno Schulz y Clarice Lispector. Como se sabe, este tipo de cruces interpretativos tiene la ventaja de refrescar la perspectiva -por fin no leemos "Casa tomada" en clave antiperonista- y abre los textos, incluso los más conocidos, a nuevas posibilidades semánticas, en un gesto claramente cortazariano. El mismo efecto se produce siempre a la hora de contrastar el original literario con sus versiones fílmicas, lo que nos demuestra Rafał Koschany, proponiendo una nueva mirada sobre la relación entre "Las babas del diablo" y Blow-up de Antonioni. El fervor comparatista del último apartado del tomo llega a su apogeo con "Sueño...", la recopilación fotográfica de las performances multimedia de Izabella Gustowska, que parace abrir los significados cortazarianos hacia el infinito.

Todas estas propuestas, algunas más, otras menos concentradas en los textos concretos de Cortázar, a veces muy ingeniosas en cuanto al marco teórico para los mismos, tienen dos ventajas principales. Primero, avivan el diálogo cultural polaco-argentino que, hoy en día,

\footnotetext{
${ }^{2}$ En un artículo publicado originalmente en Studia Filologiczne 2012/2013: 25/26.
} 
resulta menos vivo de lo que uno/a podría esperar. Y segundo, parecen tener -y lograr- el mismo objetivo, que sería jugar con el Gran Cronopio, no permitir que su obra se petrifique, ya que, como lo plantea una de los protagonistas de Olga Tokarczuk, que "plantada sobre el terraplén antiinundaciones, la mirada fija en la corriente, descubrió que -pese a todos los peligros- siempre sería mejor lo que se movía que lo estático, que sería más noble el cambio que la quietud, que lo estático estaba condenado a desmoronarse, degenerar y quedar reducido a la nada; lo móvil, en cambio, duraría incluso toda la eternidad" (Los errantes, 2019, p. 10 traducción de Agata Orzeszek).

Barbara Jaroszuk

Uniwersytet Warszawski 